\title{
DEVELOPMENT OF BIOACTIVE GLASS-CERAMIC SUBSTRATES WITH BIOCIDE ACTIVITY
}

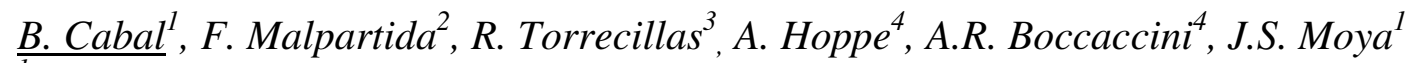
${ }^{1}$ Instituto de Ciencia de Materiales de Madrid (ICMM-CSIC), 28049, Cantoblanco, Madrid, Spain

${ }^{2}$ Centro Nacional de Biotecnología (CNB-CSIC), 28049, Cantoblanco, Madrid, Spain

${ }^{3}$ Centro de Investigación en Nanomateriales y Nanotecnología (CINN), Consejo Superior de Investigaciones Científicas (CSIC) - Universidad de Oviedo (UO) Principado de Asturias, Parque Tecnológico de Asturias, 33428, Llanera, Spain ${ }^{4}$ Institute of Biomaterials, University of Erlangen-Nuremberg, 91058, Erlangen,

Germany

\section{Abstract}

bcabal@icmm.csic.es

In the present study, the biocide efficiency of bioactive 45S5 Bioglass ${ }^{\circledR}$ derived glassceramic substrates against common Gram-positive and Gram-negative bacteria, and also against yeast was investigated. The results confirmed the high bactericidal capacity of this material. Inorganic coatings containing silver nanoparticles on glass-ceramic substrates were developed in order to ascertain if the presence of silver would enhance the biocide activity. It has been found that a coating made of soda-glass containing silver nanoparticles does not improve the antifungal properties of $45 \mathrm{~S} 5$ Bioglass ${ }^{\circledR}$ derived glass- ceramic substrates.

Keywords: Antibacterial; 45S5 Bioglass ${ }^{\circledR}$; Glass; Glass-ceramic; Silver nanoparticles; Biocide

\section{Introduction}

Bioactive glasses of silicate composition represent a group of surface reactive materials being considered for numerous biomedical applications including orthopaedic coatings, dental materials and scaffolds for bone tissue engineering [1]. To achieve enhanced mechanical strength, bioactive glasses are often sintered at high temperature to form a glass-ceramic [2]. Bioactive glasses and glass-ceramics have been investigated as candidates for bone grafts as they are Class A bioactive materials which means, that they can bond to both bone and soft tissue and can stimulate bone growth [3]. The classical 45S5 bioactive glass composition universally known as Bioglass ${ }^{\circledR}$ (composition in wt.\%: $45 \mathrm{SiO}_{2}, 24.5 \mathrm{Na}_{2} \mathrm{O}, 24.5 \mathrm{CaO}$ and $6 \mathrm{P}_{2} 0_{5}$ ) has been used in numerous medical and dental applications [1] and, more recently, as bone engineering scaffolds [4]. The in vitro and in vivo biocompatibility and biodegradability of Bioglass ${ }^{\circledR}$ have been long established [1,5], and also few studies on the antibacterial 
properties were carried out on particulate amorphous bioactive glasses revealing for example its antibacterial activity against oral bacteria [6] and against $S$. aureus, $S$. epidermidis and E. Coli bacteria [7]. Bioactive glass particles have also been tested as antibacterial agents in bone cements [8]. However, to our knowledge only one study was carried out on glass ceramic-scaffolds made of sintered Bioglass ${ }^{\circledR}$ [9], but in this case, not biocide capability against the strain tested (i.e. Staphylococcus aureus) was determined.

Over the last few years, new strategies have been proposed to control and prevent microbial contamination of implants. Although the discovery of antibiotics and the introduction of controlled hygienic protocols have remarkably minimised the risk of bacterial contamination during surgery and have decreased the danger of infection, bacterial contagions can cause implant failure, prolong times and cost of hospitalisation, and sometimes lead to the patient's death. One of the promising approaches is to adjust the antimicrobial properties of the implant surface implantation. Different surface modifications and coating techniques can be used to prevent bacteria colonization. The introduction of silver has recently become one of the preferred methods to confer microbial resiliency on biomedical materials and devices, since the incidence of biomaterial- centred infections is one of the main causes of revision surgery [10]. In this sense, glass-ceramic substrates were coated with a silver doped glass, which biocide activity was previous proved [11], in order to minimize the risk of possible microbial contamination through the potential antimicrobial activity of the leaching silver.

The objective of the research reported herein is to evaluate the potential in vitro biocide capacity of bioactive glass-ceramic substrates made from 45S5 Bioglass ${ }^{\circledR}$ and to compare it with the antimicrobial benefits of nanosilver-covered bioactive glass-ceramic substrates.

\section{Experimental}

\subsection{Materials}

45S5 Bioglass ${ }^{\circledR}$-derived glass-ceramic pellets were fabricating using commercially available Bioglass $^{\circledR}$ powder with a mean particle size of $\sim 15 \mu \mathrm{m}$. The powder was pressed to pellets (diameter $10 \mathrm{~mm}$, height $2 \mathrm{~mm}$ ) and sintered at $1050{ }^{\circ} \mathrm{C}$ for $140 \mathrm{~min}$. The heating rate was $2 \mathrm{~K} / \mathrm{min}$. 
Homogeneous dispersed silver nanoparticles embedded into glassy matrix have been obtained following a similar procedure as it is described previously [11]. Briefly, a commercial soda-lime glass with chemical composition (wt.\%): $70.20 \mathrm{SiO}_{2} ; 15.80$ $\mathrm{Na}_{2} \mathrm{O} ; 7.10 \mathrm{CaO} ; 3.20 \mathrm{MgO} ; 1.71 \mathrm{Al}_{2} \mathrm{O}_{3}, 1.06 \mathrm{~B}_{2} \mathrm{O}_{3}, 0.05 \mathrm{~K}_{2} \mathrm{O}$ and $0.02 \mathrm{Fe}_{2} \mathrm{O}_{3}$, is homogenously mixed with the corresponding quantity of vitellinate/nAg (ARGENOL S.L.) to obtain a silver doped glass with $17 \mathrm{wt}$ \% content of silver, then it is sintered in zirconia crucibles at $750^{\circ} \mathrm{C}$ for $1 \mathrm{~h}$. Cladding of the bioactive glassceramic sintered pellets was done by deposition of this powder $(0.1 \mathrm{~g})$ from homogeneous suspensions in acetone $(20 \mathrm{~mL})$ and subsequently air-dried at $40{ }^{\circ} \mathrm{C}$. Afterwards, the coated pellets were heated in an argon atmosphere at $980^{\circ} \mathrm{C}$ for $1 \mathrm{~h}$ (sample 45S5-nAg). Only one face of the pellet was covered. The target was to fabricate a nAg-glass coating of $10 \mu \mathrm{m}$ thickness on the bioactive glass-ceramic substrate.

\subsection{Characterization}

Glass-nAg powder was fully characterized by chemical analysis, TEM, UV-Vis spectrophotometer as in a previous work [11].

The morphology of the coated pellets was studied by scanning electron microscopy (SEM) (Nova ${ }^{\text {TM }}$ NanoSEM-FEI Company) using a secondary and backscattered electrons detector ( $\mathrm{vCD}$ ). The crystalline phase characterisation was carried out by $\mathrm{X}$ Ray Diffraction (XRD) in a Bruker D8 diffractometer using $\mathrm{CuK}_{\alpha}$ radiation at $40 \mathrm{kV}$ and $30 \mathrm{~mA}$. Silver particle size was studied by transmission electron microscopy (TEM) (Jeol microscope model FXII operating at $200 \mathrm{kV}$ ). Silver and calcium concentration in the resulting the supernatant after $24 \mathrm{~h}$ incubation (see below) was measured by inductively coupled plasma (ICP) analyses (ICP Perkin Elmer mod. optima 2100 DV).

\subsection{Antibacterial tests}

The antimicrobial benefits of glass-ceramic pellets 45S5 and 45S5-nAg were evaluated against three different microorganisms: Escherichia coli JM 110 (Gram-negative bacteria), Micrococcus luteus (Gram-positive bacteria) and Issatchenkia orientalis (yeast). These microorganisms were grown at $37^{\circ} \mathrm{C}$ overnight in a liquid medium. Before the experiments, $10 \mu \mathrm{L}$ of each culture was diluted in $1 \mathrm{~mL}$ of a suitable media, and cultured at $37^{\circ} \mathrm{C}$ for $6 \mathrm{~h}$. The media used were Luria Bertani (LB) for Escherichia coli JM 110 and Micrococcus luteus, and yeast extract dextrose (YEPD) for 
Issatchenkia orientalis. Subsequently, the samples were added. A silver free media (a mixture of water containing the corresponding nutrient according to the microorganism tested: LB or YEPD) was used as control. The microorganisms were tested for viability after culture on appropriate dilution from the corresponding cultures. The inoculums were incubated at $37^{\circ} \mathrm{C}$ with horizontal shaking for $24 \mathrm{~h}$. The number of viable colonies was counted. Assays were carried out in triplicate.

At the end of the growing period, cells and heavy materials debris were removed by centrifugation and the release of calcium and silver to the fermentation broth was determined by inductively coupled plasma (ICP) as mentioned above. The $\mathrm{pH}$ of the medium after biocide test was also measured.

\section{Results and Discussion}

In Figure 1 is shown TEM micrograph of silver doped glass with 17 wt.\% content of silver. It can be seen a size distribution of globular-shape silver nanoparticles range between 7-35 $\mathrm{nm}$. It can be also observed some agglomerates.

SEM micrographs of the top surface of the Bioglass ${ }^{\circledR}$ samples and of silver doped glass coatings are shown in Figure 2. As observed in these micrographs, in the silver-free pellet (Figure 2.A) pores and micro-cracks are clearly visible. During the thermal treatment at $980{ }^{\circ} \mathrm{C}$ (Figures 2.B) the porosity was closed. Silver nanoparticles present in the coating are homogenously distributed. The high temperature $\left(980^{\circ} \mathrm{C}\right)$ required to obtain the coating did not modify significantly the size of nanoparticles (Figure 2.C), it is still range between $10-40 \mathrm{~nm}$, with the presence of some agglomerates lower than $1 \mu \mathrm{m}$. Moreover, the SEM micrograph revealed that a few flake-like crystals were grown in some areas of the coating (Figure 2.D). The XRD analysis (Figure 3) enabled the precise identification of the crystalline phases in different samples. The angular location and intensity of most of the diffraction peaks of uncoated 45S5 Bioglass ${ }^{\circledR}$ derived glassceramic closely match the standard JCPDF database (22-1455), which indicates that the major crystalline phase is $\mathrm{Na}_{2} \mathrm{Ca}_{2} \mathrm{Si}_{3} \mathrm{O}_{9}$. A secondary phosphate phased, $\mathrm{Na}_{2} \mathrm{Ca}_{4}\left(\mathrm{PO}_{4}\right) \mathrm{SiO}_{4}$ (JCPDF 33-1229), was also identified. This result is in agreement with a previous study [12], in which the sintering process and crystallisation of 45S5 Bioglass ${ }^{\circledR}$ was investigated. In the case of silver coated Bioglass ${ }^{\circledR}$ derived glass ceramic samples, two extra XRD peaks at $26.17^{\circ}$ and $26.56^{\circ}$, are seen (indicated by circles) which could be ascribed to the reflections of (410) and (-202) planes of wollastonite $\left(\mathrm{CaSiO}_{3}\right)(\mathrm{JCPDF} 84-0655)$. Moreover, the two peaks at $38.32^{\circ}$ and $44.51^{\circ} \mathrm{can}$ be 
attributed to reflections from (111) and (200) planes of silver, respectively (JCPDF 870720).

Images of the cultures after biocide test and also the number of counted viable colonies are shown in Figure 4. The sintered glass-ceramic pellets (45S5 Bioglass ${ }^{\circledR}$ ) exhibit a visible antibacterial effect against the two pathogenic bacteria studied. A complete reduction of colonies of $E$. coli and M. luteus (see also the low turbidity of the cultures which contain the scaffolds after the test) is observed, whereas in the case of the yeast, the reduction of colony forming units is only of one order of magnitude. Similar results were achieved with the covered pellets (45S5-nAg).

The concentrations of $\mathrm{Ca}$ and $\mathrm{Ag}$ species in the supernatant solution after the biocide test are presented in Table 1 . The release of calcium from the silver containing bioactive glass-ceramic pellets is three times higher than that from silver free pellets. These values are quite close to those found for particulate glass [13], which indicates that a partial material disintegration occurs. In contrast, it is noteworthy that the rate of dissolution of silver species is significantly slow. Very low amount of silver was detected after the biocide tests, which can be translated in the specific kinetics of silver ion release from the glass. This could open the possibility to consider this material as a $\mathrm{Ag}^{+}$local delivery device of a long lasting, which could be used to prevent implantassociated infections by reducing the concentration of bacteria and/or impeding bacterial adherence to the implant surface, but further kinetic studies would have to be carried out.

Some researchers have evaluated the biocide capacity of the bioactive glasses 45S5 Bioglass ${ }^{\circledR}$. Most of them were carried out on particulate Bioglass ${ }^{\circledR}[6,7,13,14,15]$, only Gorriti et al. [9] evaluated the biocide capacity of glass-ceramic scaffolds made from sintered 45S5 Bioglass ${ }^{\circledR}$ for the first time. In many of these studies it was concluded that bioactive glasses possessed antibacterial effect on common bacteria due to the high aqueous $\mathrm{pH}$ value caused by the bioactive glass dissolution. In our study, regarding the values of $\mathrm{pH}$ measured after the biocide tests (Table 2), there was an evident increase of the $\mathrm{pH}$ of the medium, but it is not significantly higher than the $\mathrm{pH}$ of the fermentation broth at the end of the growth. Therefore, it was not possible to conclude from these experiments that the antibacterial activity was due to a high $\mathrm{pH}$ per se. Neither could this activity be attributed to the effect of silver presents in the coating. In the case of E. coli or M. luteus, the bactericidal effect of the samples is so pronounced that it is impossible to determine if $\mathrm{Ag}$ release improves or not its 
bactericidal capacity. However, in the case of I. orientalis no effect is detected. The quantity of silver released in this situation after $24 \mathrm{~h}$ was not enough to diminish more than one order of magnitude the number of colony forming units, e.g., the activity was similar to that achieved by the bioactive glass-ceramic substrates.

The antibacterial activity of these scaffolds could be explained by the same mechanism operating in the case of E. coli, M. luteus, C. krusei, reported by Moya et al. [13] or in the case of S. aureus, S. epidermidis, E. coli, reported by Hu et al. [7]. As it is reported by these authors, there is a microbial adhesion on glass particles, probably due to electrostatic forces between the negatively charged glass particles and the positively charged outer surface of the cell membranes during the actively growing stage [13]. The glass-membrane interface is crucial for the biocide activity. This adhesion should result in a high calcium concentration release in the proximity of the plasma membrane, distorting the membrane electrochemical potential gradient, and therefore causing the cell death. Based on this mechanism the observed biocide activity of the samples can be rationalized. This effect is evident in the case of $I$. orientalis. Both materials tested (coated and uncoated 45S5 Bioglass ${ }^{\circledR}$ ) released the same quantity of calcium and achieved the same biocide activity.

\section{Conclusions}

The results obtained in the present work provides in vitro evidence that bioactive glass-ceramics made from sintered $45 \mathrm{~S} 5$ Bioglass ${ }^{\circledR}$ exhibit biocidal capacity against two common bacteria. The high activity of these bioactive glass-ceramic scaffolds is very promising. This opens the possibility to use them directly, without any additional modification (such as surface modification by coating with silver doped glass), in a broad spectrum of applications in which the control of unwanted microbial population is required. Although the incorporation of silver coating did not improve the biocide capacity of Bioglass ${ }^{\circledR}$-derived glass-ceramic after $24 \mathrm{~h}$, it should be emphasized that the kinetic of silver release is significantly slow in the present coating system.

\section{Acknowledgments}

The authors acknowledge financial support from the Spanish Ministry of Science and Innovation (Bio2008-03683) and funding from the ITMA-CSIC Research Cooperative Project. 


\section{Captions to Figures}

Figure 1. TEM micrograph of silver doped glass powder (17 wt\% nAg)

Figure 2. SEM micrographs of: A) bioactive glass-ceramic substrate (45S5 Bioglass ${ }^{\circledR}$ derived) and $B-C-D)$ silver coated substrate (45S5-nAg) at different magnifications.

Figure 3. XRD patterns of coated (45S5-nAg) and uncoated $45 S 5$ Bioglass ${ }^{\circledR}$ - derived glass ceramic substrate.

Figure 4. Images after biocide test (on the left). CFU $m L^{-1}$ of E. coli, M. luteus and I. orientalis corresponding to the biocide agents at $24 \mathrm{~h}$ (on the right).

\section{Captions to Tables}

Table 1. ICP analysis of calcium and silver lixiviated after 24 h of biocide test.

Table 2. $p H$ of the medium after biocide test.

\section{References}

[1] L.L. Hench. Bioceramics. J. Am. Ceram. Soc. 81 (1998) 1705-1728.

[2] L. Lefebvre, L. Gremillard, J. Chevalier, R. Zenati, D1 Bernache-Assolant. Sintering behaviour of 45S5 bioactive glass. Acta Biomater. 4 (2008) 1894-1903.

[3] L.L. Hench, J.M. Polak. Third-generation biomedical materials. Science 295 (2002) 1014-1017.

[4] Q.Z. Chen, I.D. Thompson, A.R. Boccaccini. 45S5 Bioglass ${ }^{\circledR}$-derived glass-ceramic scaffolds for bone tissue engineering. Biomaterials 27(11) (2006) 2414-2425.

[5] J. Wilson, A. Yli-Urpo, R.P. Happonen. Bioactive glasses: Clinical applications. In: L.L. Hench, J. Wilson, editors. An introduction to Bioceramics. Singapore: World Scientific Publishing Co.; 1993 p.63-73.

[6] I. Allan, H. Newman, M. Wilson. Antibacterial activity of particulate Bioglass ${ }^{\circledR}$ against supra- and subgingival bacteria. Biomaterials 22 (2001) 1683-1687.

[7] S. Hu, J. Chang, M. Liu, C. Ning. Study on antibacterial effect of 45S5. J. Mater. Sci: Mater. Med. 20 (2009) 281-286.

[8] Koller G, Roether J, Bruce K, Deb S. Antimicrobial potential of bioactive bone cements. Journal of Applied Biomaterials \& Biomechanics 6 (1) (2008) 16-22. 
[9] M.F. Gorriti, J.M. Porto López, A.R. Boccaccini, C. Audisio, A.A. Gorustovich. In vitro study of the antibacterial activity of bioactive glass-ceramic scaffolds. Advanced Engineering Materials 11 (2009) B67-B70.

[10] D.R. Monteiro, L.F. Gorup, A.S. Takamiya, A.C. Ruvollo-Filho, E.R.d. Camargo, D.B. Barbosa. The growing importance of materials that prevent microbial adhesion: antimicrobial effect of medical devices containing silver. International Journal of Antimicrobial Agents 34 (2009) 103-110.

[11] L. Esteban-Tejeda, F. Malpartida, C. Pecharromán, J.S. Moya. High Antibacterial and antifungal activity of silver monodispersed nanoparticles embedded in a glassy matrix. Advanced Engineering Materials 12 (7) (2010) B292-B297.

[12] O. Bretcanu, S. Chatzistavrou, K. Paraskevopoulos, R. Conradt, I. Thompson, A.R. Boccaccini. Sintering and crystallisation of $45 \mathrm{~S} 5$ Bioglass ${ }^{\circledR}$ powder. Journal of the European Ceramic Society 29 (2009) 3299-3306.

[13] J.S. Moya, L. Esteban-Tejeda, C. Pecharromán, S. R. Mello, A. C. da Silva, F. Malpartida. Glass powders with a high content of calcium oxide: a step toward a "green" universal biocide. Advanced Biomaterials, in press.

[14] I. Allan, H. Newman, M. Wilson. Particulate Bioglass ${ }^{\circledR}$ reduces the viability of bacteria biofilm formed on its surface in an in vitro model. Clinical Oral Implants Research 13 (2002) 53-58.

[15] M. Cerruti, D. Greenspan, K. Powers. Effect of $\mathrm{pH}$ and ionic strength on the reactivity of Bioglass ${ }^{\circledR}$ 45S5. Biomaterials 26 (2005) 1665-1674. 


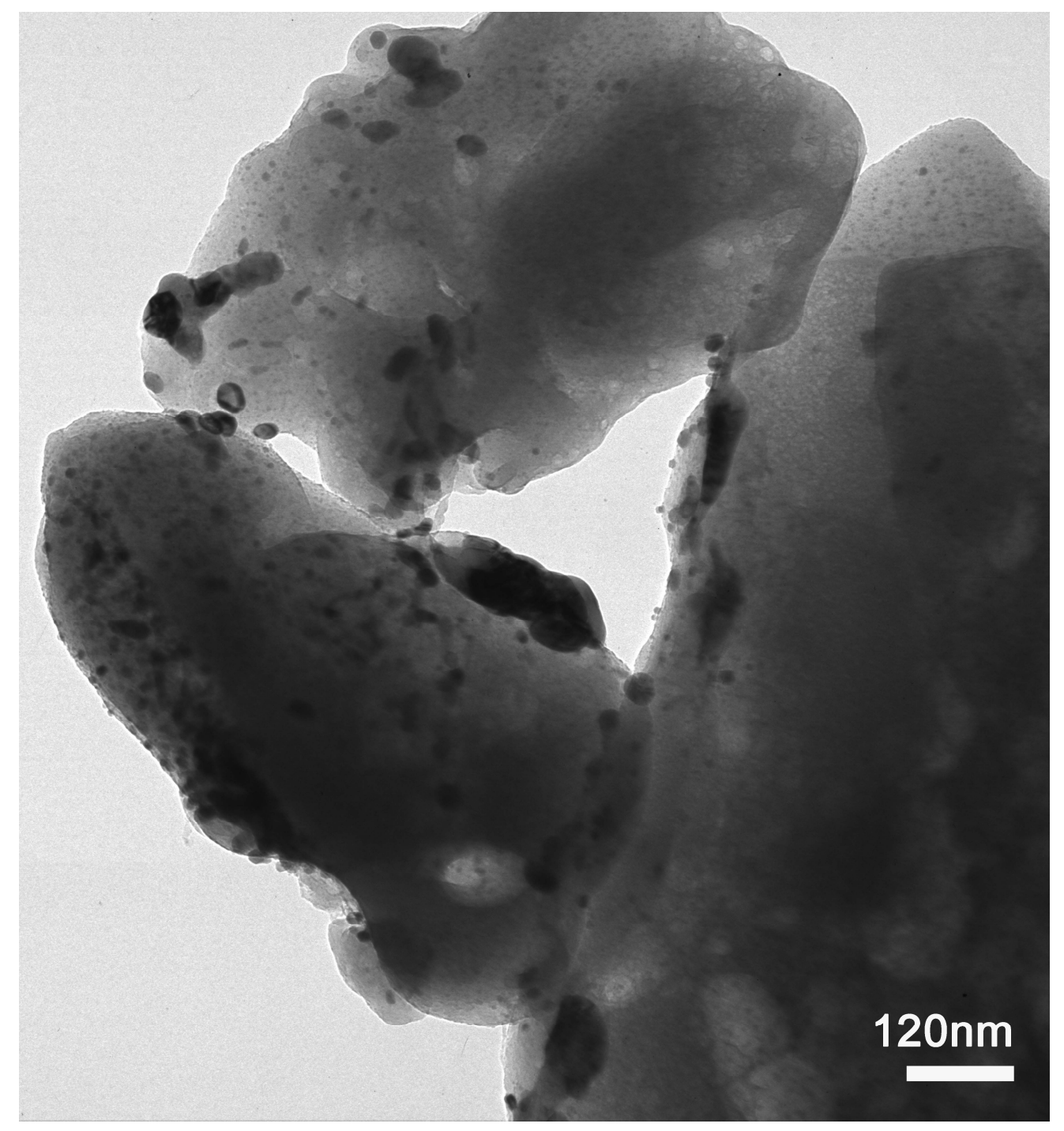

TEM micrograph of silver doped glass powder (17 wt\% nAg) $1625 \times 1755 \mathrm{~mm}(72 \times 72 \mathrm{DPI})$ 
Figure 2
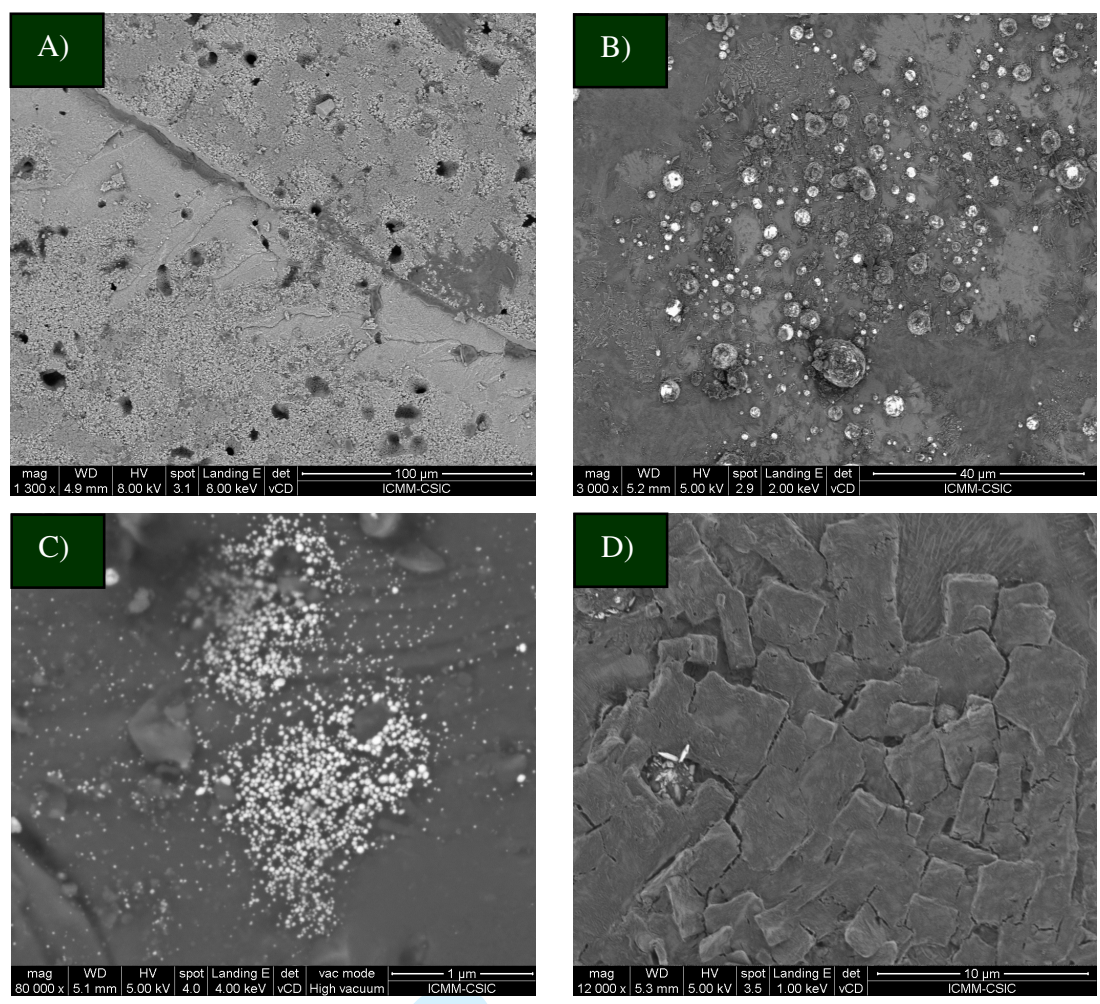


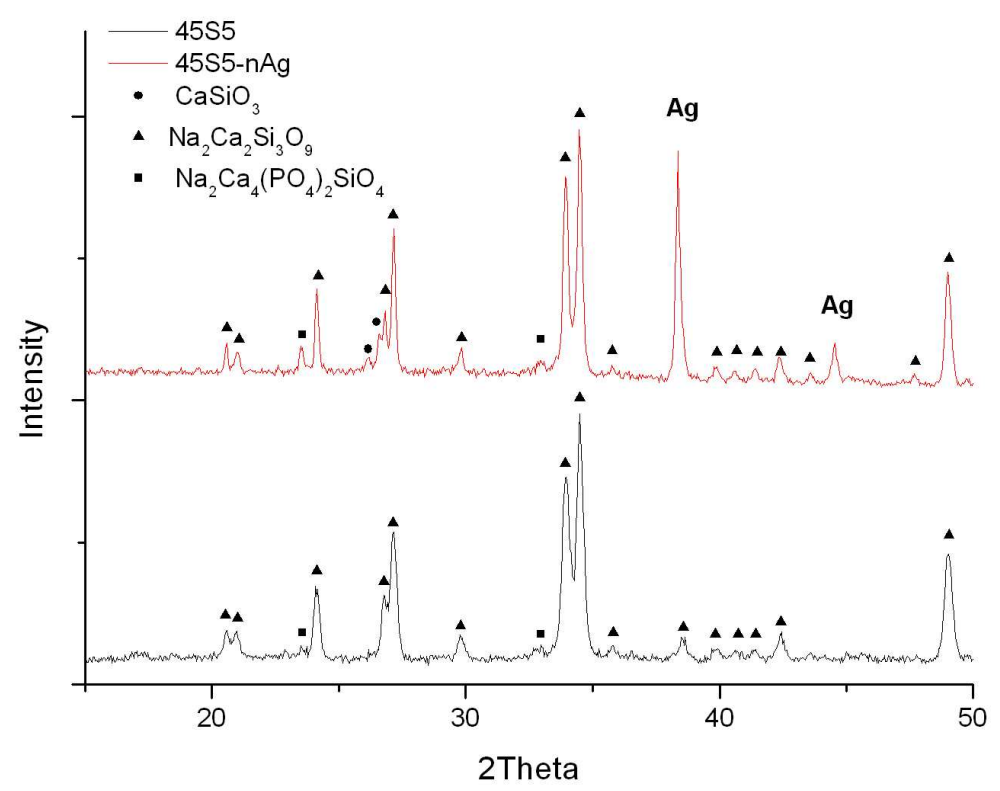

XRD patterns of coated (45S5-nAg) and uncoated $45 S 5$ Bioglass $(\mathbb{2}$ - derived glass ceramic substrate. $289 \times 202 \mathrm{~mm}(150 \times 150 \mathrm{DPI})$ 
Figure 4.

E. coli

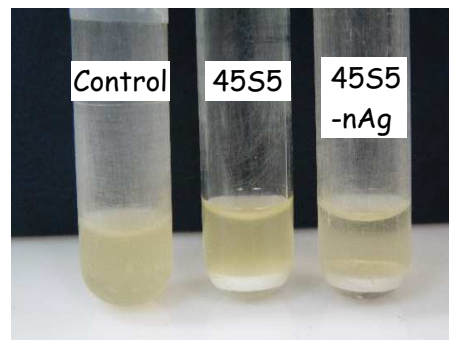

\begin{tabular}{|l|c|}
\cline { 2 - 2 } \multicolumn{1}{c|}{} & CFU $\left(\mathrm{mL}^{-\mathbf{1}}\right)$ \\
\hline Control & $2.0 \times 10^{10}$ \\
45S5 & bdl $\left(<10^{3}\right)$ \\
45S5-nAg & $3.0 \times 10^{3}$ \\
\hline
\end{tabular}

\section{M. luteus}

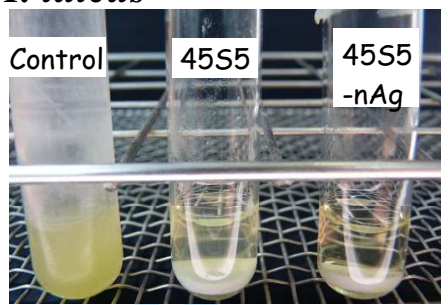

\begin{tabular}{|l|c|}
\cline { 2 - 2 } \multicolumn{1}{c|}{} & CFU $\left(\mathbf{m L}^{-1}\right)$ \\
\hline Control & $2.2 \times 10^{9}$ \\
45S5 & bdl $\left(<10^{3}\right)$ \\
45S5-nAg & bdl $\left(<10^{3}\right)$ \\
\hline
\end{tabular}

\section{I. orientalis}

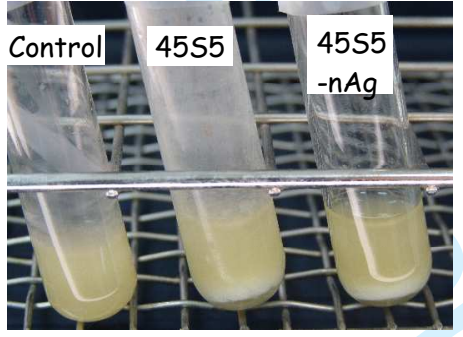

\begin{tabular}{|l|c|}
\cline { 2 - 2 } \multicolumn{1}{c|}{} & CFU $\left(\mathbf{m L}^{-1}\right)$ \\
\hline Control & $2.6 \times 10^{12}$ \\
45S5 & $1.8 \times 10^{11}$ \\
45S5-nAg & $4.3 \times 10^{11}$ \\
\hline
\end{tabular}


Table 1.

\begin{tabular}{lccc}
\hline Microorganism & $\begin{array}{c}\text { Ca in solution (ppm) } \\
45 \mathrm{~S} 5\end{array}$ & $\begin{array}{c}\text { Ca in solution }(\mathrm{ppm}) \\
\text { 45S5-nAg }\end{array}$ & $\begin{array}{c}\text { Ag in solution (ppm) } \\
\text { 45S5-nAg }\end{array}$ \\
\hline E. coli & 75.45 & 217.5 & 0.761 \\
M. luteus & 73.87 & 225.6 & bdl \\
I. orientalis & 364.1 & 398.2 & 2.956
\end{tabular}

Table 2.

\begin{tabular}{lccc}
\hline Microorganism & $\begin{array}{c}\mathrm{pH} \\
\text { Control }\end{array}$ & $\begin{array}{c}\mathrm{pH} \\
\text { 45S5 }\end{array}$ & $\begin{array}{c}\mathrm{pH} \\
\text { 45S5-nAg }\end{array}$ \\
\hline E. coli & 8.7 & 9.5 & 9.2 \\
M. luteus & 8.9 & 9.7 & 9.6 \\
I. orientalis & 7.2 & 8.7 & 8.7
\end{tabular}

